\title{
Investors' risk perception in the context of efficient market hypothesis: A conceptual framework for malaysian and indonesian stock exchange
}

\author{
Syed Emad Azhar Ali ${ }^{1 *}$, Fong-Woon Lai ${ }^{2}$, and Muhammad Kashif Shad ${ }^{3}$ \\ 1,2,3 Department of Management \& Humanities, Universiti Teknologi PETRONAS,32610, Perak Darul \\ Ridzuan, Malaysia
}

\begin{abstract}
The advocates of the Efficient Market Hypothesis (EMH) theory postulates that share prices depict all the available information concerning its intrinsic worth. EMH espouses the Random Walk Theory i.e. future stock returns cannot be predicted based on past movement patterns. Contrary to that, there are believers of the Adaptive Market Hypothesis (AMH) who have questioned the adaptability of EMH and argues that market efficiency and investor's risk perception varies across time, thus, stock returns can be predicted through active portfolio management. Various Studies have argued on market efficiency debate for developed markets, however, limited studies have examined the same for emerging markets such as Malaysia and Indonesia, which are most volatile among ASEAN-5 indices. Therefore, the primary objective of this study is to conceptualize the manifestation of efficient market hypothesis and investors' risk perception in volatile markets of Malaysia (Kuala Lumpur Composite Index) and Indonesia (Jakarta Composite Index) by testing the 10 years (2010-2019) of daily, weekly and monthly data for the return predictability. The findings of this study will provide insight into stock market behavior to help investors to better strategize their portfolio investment positioning to reap the most efficient risk-based return.
\end{abstract}
Keywords- Adaptive Market Hypothesis, Random Walk, Return Predictability, Volatility, Risk-reward profile

\section{Introduction}

A blindfolded monkey throwing darts at a newspaper's financial pages could select a portfolio that would do just as well as one carefully selected by experts" states Malkiel in his book "A Random Walk Down Wall Street: The Time-Tested Strategy for Successful Investing" (2007) (Malkiel, 2007; Reilly \& Brown, 2011). The premise of the statement is still researched and debated - the "Efficient Market Hypothesis" (EMH) proposed by (Fama, 1991; Fama \& French, 1988). The innocuous hypothesis that "share prices fully reflect all available information" is quite onerous. EMH in its weak form says that the security prices follow random walk i.e. past security returns cannot be used to forecast future stock gains. Thus, a weak form of EMH implies the impossibility of excess returns using technical/ trading rules. The semi-strong form of EMH postulates that the share prices depict all public information for example annual reports, stock splits, etc. Thus, by using the fundamental analysis and trading rulebooks, additional returns cannot be obtained. Therefore, a simple

*Corresponding Author: syed_17007896@utp.edu.my 
buy and hold plan would outperform any active portfolio management and hence Malkiel's statement.

Contrary to the believers of EMH, various studies have found that the random walk is not followed by the markets and that there is a certain probability of the market returns. (De Bondt \& Thaler, 1985; Jegadeesh \& Titman, 1993; A. W. Lo, 2004, 2005; A. W. Lo \& MacKinlay, 1988 ) to name a few. Lo being a top critic of EMH argues that investor's behavior is based on rationality and thus has emphasized many behavioral prejudices that plague human decision making (A. W. Lo, 2005). Motivated from the portfolio theory by (Shefrin \& Statman, 2000) and the utility theory by (Kahneman \& Tversky, 1979) in which behavioral aspects have been incorporated, (A. Lo, 2004) recommends the adaptive market hypothesis (AMH) to resolve the behavioral biases with EMH. However, adaptive market hypothesis (AMH) delivers only a descriptive framework, but it does provide the below mentioned insights (A. W. Lo, 2005) :

i. The efficiency varies across time and the geographies, yet the markets are not always efficient. Active portfolio management could provide excess returns by exploiting the path followed by the stock market and the changes in investor behavior.

ii. By the time, the risk perceptions of the investors change.

iii. The equity risk premium will have a variable nature and will be dependent on the demographics and the stock market path of the investors.

\subsection{The Case for Malaysian and Indonesian Stock Exchanges:}

The phenomenal economic growth and development of the Association of Southeast Asian Nations (ASEAN) region over the last two decades have resulted in a significant inflow of foreign investment. The financial markets of ASEAN particularly of Indonesia and Malaysia have also improved and amend their procedures to facilitate foreign investment (Wang \& Liu, 2016). As a result, the international investors have been attracted by the above reasons, who started looking for opportunities to differentiate their portfolios from any other investments by exploring higher returns. The investors are meticulous about high gains at the price of reasonable and measurable risk. To the best of the authors' knowledge, only a few studies have examined the ASEAN-5 stock index returns, such as the studies of (Guidi \& Gupta, 2012; Kiwiriyakun, 2013). Therefore, this study will evaluate the investors' risk perception in stock exchanges of the uala Lumpur Stock Exchange (KLSE) and the Jakarta Stock Exchange (JSX).

To test the different levels of market efficiency, the study use the Ljung-Box test (Ljung $\&$ Box, 1978) to the fixed-length rolling subsample windows. There could be a two-fold contribution to this study: first, the study will test the market efficiency in the context of Malaysian and Indonesian Stock Market using various subsample windows. Secondly, the study will also explore the variant risk perception prevalent in both financial markets. Given the context of EMH and the contrary arguments presented by $\mathrm{AMH}$, this study will inquire the following research questions:

RQ1: How the market efficiency differs between KLSE and JSX measured by the predictability of returns?

\section{RQ2: How does the risk-return profile differ between KLSE and JSX?}

RQ3: Do the risk-premium differs between KLSE and JSX?

In line with the above research questions, the study will aim for the following research objectives:

RO1: To evaluate the market efficiency for KLSE and JSX measured by the predictability of returns.

RO2: To analyze of the risk-return profile for KLSE and JSX in the light of EMH. 
RO3: To compare and rationalize the risk-premium for KSLE and JSX in the light of EMH.

The setting and forming of the remaining paper are as follows. In the second segment, we presented the literature review. The third segment will highlight the methodology along with the statistical tests necessary to answer our research questions. The fourth segment will shed light on the implications. Lastly, the fifth segment covers the overall paper's conclusion.

\section{Literature Review}

Efficient Market Hypothesis is grounded on the notion that share prices adjust quickly with the inflow of any new information, thus, current prices of a share depict all the information which is publicly available concerning that share. Hence, the chances of abnormal gain on the base of available information are rarely possible.

Based on information available in the market, EMH has been classified by Fama (Fama et al., 1969) in three groups i. weak-form EMH, ii. Semi-strong-form EMH and iii. Strong-form EMH. The weak form of EMH is usually tested through the Random Walk Model (RWM) which advocates that the price changes are sovereign and cannot be predicted through the behavior of stock prices in the past. Inefficiency indications will compel to the regulatory authorities to take compulsory steps to avoid such a scenario and restructure to accurate it (S. E. A. Ali, Lai, Dominic, et al., 2021)2.1 Studies on market efficiency:

Various studies have been conducted on the subject of market efficiency and the random walk model in different stock markets. References (Malkiel \& Fama, 1970); (Fama, 1991; Granger, 1975; Hawawini, 1984); and (A. W. Lo, 1997) comprehensively examined the RWM and found evidence in support of EMH. (Solnik, 1973) tested the EMH for 8 European stock markets and observed that deviations from RWM are more prominent in European stocks as compared to US. (Ang \& Pohlman, 1978) tested five far Eastern equity stock markets of Japan, Singapore, Australia, and Hong Kong and the Philippine with a conclusion that markets are slightly efficient in the weakest form.

Other than the types of studies, an argument is also found in the literature concerning appropriate statistical testing being employed in each study. These tests are characterized into two clusters. The first cluster is formed on historical information from the market that will depict the risk-return relationship. Whereas, the second cluster focuses on the test of independence among rates of return such as autocorrelation and runs test.

Contrary, to the school of thought of $\mathrm{EMH}$, there are advocates, growing in numbers for Adaptive Market Hypothesis (AMH) as proposed by (A. W. Lo, 2004, 2005). Among those advocates, are (S. E. A. Ali, Lai, Hassan, et al., 2021; Alvarez-Ramirez et al., 2012; Ito \& Sugiyama, 2009; Kim et al., 2011; Lim, 2007; Lim \& Brooks, 2006).

Though many studies have examined the behavior of stock markets in the context of EMH and that of $\mathrm{AMH}$, there are some limitations. Most of the studies have considered the timevarying effect on returns and their lags. However, studies exploring the investors' risk perceptions in the light of volatile markets like the Kuala Lumpur Stock Exchange (KLSE) and the Jakarta Stock Exchange (JSE). Furthermore, an argument is present especially for statistical tests employed for testing the market efficiency. Therefore, this study will conceptualize the use of three different tests namely the Ljung Box Test, Mackinlay Variance Ratio Test, and Chow Denning Heteroscedasticity Test. In light of the above discussions, the first hypothesis for this study will be formulated as:

$\boldsymbol{H}_{1}:$ The market efficiency measured by different tests of predictability differs significantly between KLSE and JSX. 


\subsection{Risk-reward Relationship}

To demonstrate the market efficiency, CAPM was used initially but once the pitfalls of CAPM were identified by (Friend et al., 1970; Jensen, 1968; Sharpe, 1966), a shift was witnessed to arbitrage pricing model (APM) to explore the equity's risk-reward relationship. The development of arbitrage pricing leads to the modelling of the Sharpe ratio for the riskreturn ratio (Roll, 1977; Ross, 1976). Since then, the Sharpe ratio has been used in many studies under the context of an efficient market hypothesis. Very few studies have compared the performance of the benchmark portfolio with that of the index such as (Bogle, 1999).

The question that arises from previous studies is whether the volatile nature of stock markets will affect the risk-adjusted return for investors. That is either, the risk-adjusted returns meet the market or beat the market. Especially, if the period of insignificance matches with the inefficiency period concluded through Ljung Box-Q statistic. Based on the varying degree of market efficiency debate and the discussion framed in this paper, it is hypothesized that changes in market efficiency will affect the risk-reward relationship for investors in KLSE and JSX.

$\mathbf{H}_{2}$ : Changes in market efficiency will significantly affect the risk-reward relationship for KLSE and JSX.

\subsection{Market Risk Premium}

Another determinant for investment decision is the analysis of risk premium either the investment involves the acquisition of real or financial assets (Cochrane, 2011). It is the additional return expected on equity investment in comparison to risk-free investment (Dimson et al., 2003). According to (Gagliardini et al., 2016), the risk premium is the reward for absorbing the systematic risk, understood as the compensation required by investors in exchange for taking a systematic risk, is the key element in setting the valuation of a financial asset (Syed Emad Azhar, Ali, Fong-Woon, Lai and Rohail, 2020).

According to (A. W. Lo, 2005), risk premium in a market follows the footsteps of the stock market and demographics of investors (S. E. A. Ali \& Khurram, 2017). The change in investors' risk perceptions over the period will also cause a change in the risk premium. Such a change in investor's risk perceptions will be dependent on the risk premium factors around the market participants and how they interact with the natural resources of market ecology. On the grounds of behavioral contributions by (A. W. Lo, 2005) and especially in the light of ineevestor risk perceptions, this study will present a hypothesis for risk premium especially in the context of changing market efficiency for KLSE and JSX.

H3: Changes in market efficiency will significantly affect the risk premium for KLSE and JSX.

\section{Methodology}

This study will examine the efficient market hypothesis for the Malaysian (Kuala Lumpur Composite Index) and Indonesian (Jakarta Composite Index) stock markets by testing the 10 years (2009-2018) of daily, weekly and monthly data for the return predictability. Extensive data for returns, risk-free rate and risk variation in the form of standard deviation is expected to be retrieved from Thomson Reuters Data Stream. Market returns are computed as follows.

$R_{t}=\ln \left(P_{t} / P_{t-1}\right)$

$P_{t}=$ Market Price at time ' $t$ '

$\mathrm{P}_{\mathrm{t}-1}=$ Market Price at time ${ }^{\mathrm{t}} \mathrm{t}-1$ ' 


\subsection{Auto Correlation and Ljung Box Statistics}

The return predictability or the random walk hypothesis is traditionally tested by applying various tests such as the Ljung-Box, variance ratio tests, etc. to the complete dataset. Thus, this study will apply these tests to the full data set to juxtapose the complete dataset results against those obtained by applying these tests to the rolling window of fixed length to the data set. According to the null hypothesis for these tests in the context of this study, if the return follows a random walk, then all its autocorrelation should be zero. Ljung and Box (1978) proposed the following Q statistic that sums the squared autocorrelations $\rho^{2}(k)$ and detects the departure from zero autocorrelations in either direction for the given number of $\mathrm{m}$ lags. The statistic $Q(m)$ incorporates the finite sample correction and is chi-square distributed with $\mathrm{m}$ degree of freedom (Campbell, Lo and Mackinlay, 1997).

$$
Q(m)=\mathrm{T}(\mathrm{T}+2) \sum_{k=1}^{m}\left(\frac{p^{2}(k)}{T-k}\right)
$$

\subsection{Unit Root Tests}

To examine the presence of unit root in time series indices Augmented Dickey-Fuller (ADF) test is generally applied. It is one of the most well-known techniques to test the stationary in time series. It is inferred from the OLS as follows:

$$
\Delta R t=b_{0}+b_{1}+\pi_{0} R_{t-1}+\sum_{t=1}^{j} \psi_{i} \Delta R_{i t-1}+\epsilon_{t}
$$

$\mathrm{R}_{\mathrm{t}}=$ is the price at time $\mathrm{t}$,

$\Delta R_{t}=$ change in price

Testing for the uncorrelated increments using a portmanteau test such as the Ljung- Box test, provides the weakest evidence for the random walk hypothesis and return predictability because uncorrelated increments do not imply independence. Lo and Mackinlay (1988) state that as the alternative hypothesis is loosely specified in a portmanteau test, tests such as variance ratio test, where the alternative hypothesis is identified, serve as a better test for testing the random walk hypothesis. The variance of the increments should be a linear function of time as infers by the random walk hypothesis. Hence, the variance ratio, $(k)$ of the variance of $k^{\text {th }}$ holding period return and $k \times$ variance of one holding period return should be unity. For example, for a stationary time series, the ratio of the variances (2) of the two-period log-returns $\mathrm{r}_{\mathrm{t}}(2)=r_{t}+r_{t-1}$ to twice the variance of one period return $r_{t}$ is given as (equation 4, Lo Mackinlay 1988, Campbell et. al. 1997):

$$
\operatorname{VR}(2)=\frac{\operatorname{Var}\left[r_{t}(2)\right]}{2 \operatorname{Var}\left[r_{t}\right]}=\frac{\operatorname{Var}\left[r_{t}+r_{t-1}\right]}{2 \operatorname{Var}\left[r_{t}\right]}=\frac{\operatorname{Var}\left[r_{t}\right]+2 \operatorname{Cov}\left[r_{t}, r_{t-1] \backslash}\right]}{2 \operatorname{Var}\left[R_{t}\right]}
$$

$\operatorname{VR}(2)=1+p(1)$

Where $\mathrm{p}(1)$ is the first-order autocorrelation. If the log returns are IID i.e. independent and identically distributed, then all autocorrelations are zero and VR $(2)=1$. If the first-order autocorrelation is positive then VR $(2)>1$ and if negative, VR (2) <1. Lo and Mackinlay (1988) extend the two-period variance-ratio to a general $\mathrm{k}$ period variance ratio as follows:

$\operatorname{VR}(k)=\operatorname{Var}\left[r_{t}(k)\right] \frac{\operatorname{Var}\left[r_{t}(k)\right]}{k \operatorname{Var}\left[r_{t}\right]}=1+2 \sum_{q=1}^{k-1}\left(1-\frac{q}{k}\right) p(q)$

Where $\mathrm{p}(q)$ is the qth autocorrelation of $r t$ and $(q)=r t+r t-1+\cdots+r t-q+1$. Thus VR $(k)$ is a linear combination of autocorrelations of $r t$ with declining weights. For all $q \geq 1$, if $(q)$ $=0$, then $(q)=1$. Lo Mackinlay (1988) showed that this variance ratio was biased and thus proposed a statistic based on, the biased corrected variance ratio6, $(k)$. They standardized this corrected ratio to get an asymptotically standard normal test statistic $\psi(k)$ (equation 6). 
$\psi(k)=\sqrt{n k}(\operatorname{VR}(\mathrm{k})-1)\left[\frac{2(2 k-1)(k-1)}{3 k}\right]^{\frac{-1}{2}} \sim \mathrm{N}(0,1)$

\subsection{Measuring Risk-reward Relationship}

Sharpe Ratio is one of the most extensively employed methods for calculating risk-adjusted reward on an investment. From an investors' perspective, it is vital to account for the risks due to which the returns might be lower than expected. Technically, it is the return per unit of risk. If the analysis depicts that the realized rolling Sharpe ratios for both indices are not constant. Especially, the cyclicality in daily, weekly and monthly log returns will be an interesting aspect to analyze. Because that indicates the presence of AMH due to unstable risk-reward relationship. Mathematically, it is the excess return per unit of risk. It is proposed to be calculated through the following formula:

Where,

$$
\text { Sharpe Ratio }=\left(R_{m}-R_{f}\right) / \sigma_{r}
$$

$\mathrm{R}_{\mathrm{m}}=$ the average annual return of the market,

$\mathrm{R}_{\mathrm{f}}=$ Risk-free rate of return

$\sigma_{\mathrm{r}}=$ the annualized standard deviation of the return/volatility

\subsection{Measuring Risk Premium}

It is the excess of market return over risk-free rate or the rate for treasury bills. From Modern Portfolio Theory and Capital Asset Pricing Model (CAPM), the risk premium has a very vital significance, therefore the slope of risk premium will exactly equal the slope of the security market line (SML) in CAPM model.

The determination of risk premium also determines the trio: required returns, historical returns, and expected returns. The required and expected returns are subjective and depend on the investors' risk-taking behavior in each market. However, the historical market risk premium will be the same for all investors as it is determined on actual happenings.

The realized risk premia are measured as the historical mean of the realized market returns over the risk-free. It is expected that equity risk premia vary so as the risk perceptions in these stock markets. The insights of AMH is that the risk perceptions are not constant but are constantly shaped by the changing market conditions (A. W. Lo, 2005). Mathematically,

Market Risk Premium $=$ Expected Rate of Return - Risk-Free Rate

\section{Implications}

The major motivation of this paper is to conceptually challenge the random walk hypothesis by analyzing the predictability of stock prices and returns. In contrast to the traditional approach of testing market efficiency, this study proposes an in-depth analysis of market efficiency based on daily, weekly and monthly data. Moreover, the study will also analyze the risk-reward relationship and risk premium in the context of two theories: EMH and AMH. Adding on, the study also proposes a wide range of statistical tests on which robustness is expected to be higher than the one used in past studies.

The results of this study are expected to provide new insight into EMH theory by predicting the stock returns based on certain risk perceptions. Moreover, the results of this study are also expected to provide an extension of EMH theory under the context of emerging markets such as Malaysia and Indonesia. The results of this study are expected to help the authorities in regulating financial markets and for investors especially when they want to earn long term returns at minimum risk.

\section{Conclusion}


This study proposes to test the efficient market hypothesis for Malaysian (KLSE) and Indonesian (JSE) stock markets by analyzing the 10 years of daily, weekly and monthly data for the return predictability. According to $\mathrm{AMH}$, risk perceptions are adaptive to changing market conditions. Thus, the testing will also analyze the resulting impact of market efficiency on the risk-reward relationship (Sharpe Ratio) and risk premium. The study also proposes to test the time-varying return predictability by employing the Ljung-Box test and the Chow - Denning heteroscedasticity consistent variance ratio test to various sub-sample windows of days, weeks and months. The results gained from this study will provide a comparative analysis of the two most volatile markets of ASEAN-5.

The outcomes from this study are expected provide better insight for the most volatile stock markets of ASEAN-5 which can assist investors in managing the most efficient riskbased return.

\section{Acknowledgment}

This work was funded by the Management \& Humanities Department, Universiti Teknologi PETRONAS (UTP) and Faculty of Business and Economics, Universitas Islam Indonesia (UII) under grant cost centre: 015MEO-114. The conference fee was funded through this grant. The authors would also like to thank Centre of Social Innovation (COSI), UTP and Institute of Self-Sustainable Building (ISB), UTP to facilitate this research study.

\section{References}

Ali, S. E. A., \& Khurram, S. (2017). Impact of demographic and health factors on GDP growth of South Asian Countries. International Journal of Academic Research in Business and Social Sciences, 7(3), 166-179.

Ali, S. E. A., Lai, F.-W., Dominic, P. D. D., Brown, N. J., Lowry, P. B. B., \& Ali, R. F. (2021). Stock market reactions to favorable and unfavorable information security events: A systematic literature review. Computers \& Security, 110(November), 102451.

Ali, S. E. A., Lai, F.-W., Hassan, R., \& Shad, M. K. (2021). The Long-Run Impact of Information Security Breach Announcements on Investors' Confidence: The Context of Efficient Market Hypothesis. Sustainability, 13(3), 1066.

Ali, S. E. A. L. F.-W. and H. R. (2020). Socio-Economic Factors On Sector-Wide Systematic Risk Of Information Security Breaches: Conceptual Framework. European Proceedings of Social and Behavioural Sciences, 502-512. https://doi.org/10.15405/epsbs.2020.12.05.54

Alvarez-Ramirez, J., Rodriguez, E., \& Espinosa-Paredes, G. (2012). Is the US stock market becoming weakly efficient over time? Evidence from 80 -year-long data. Physica A: Statistical Mechanics and Its Applications, 391(22), 5643-5647.

Ang, J. S., \& Pohlman, R. A. (1978). A note on the price behavior of Far Eastern stocks. Journal of International Business Studies, 103-107.

Bogle, J. C. (1999). Common sense on mutual funds: New imperatives for the intelligent investor. John Wiley \& Sons.

Cochrane, J. H. (2011). Presidential address: Discount rates. The Journal of Finance, 66(4), 1047-1108.

De Bondt, W. F. M., \& Thaler, R. (1985). Does the stock market overreact? The Journal of Finance, 40(3), 793-805.

Dimson, E., Marsh, P., \& Staunton, M. (2003). Global evidence on the equity risk premium. Journal of Applied Corporate Finance, 15(4), 27-38.

Fama, E. F. (1991). Efficient Capital Markets: II. The Journal of Finance, 46(5), 1575. https://doi.org/10.2307/2328565 
Fama, E. F., Fisher, L., Jensen, M. C., \& Roll, R. (1969). The Adjustment of Stock Prices to New Information. International Economic Review, 10(1), 1. https://doi.org/10.2307/2525569

Fama, E. F., \& French, K. R. (1988). Permanent and temporary components of stock prices. Journal of Political Economy, 96(2), 246-273.

Friend, I., Blume, M., \& Crockett, J. (1970). Mutual funds and other institutional investors: a new perspective. McGraw-Hill Companies.

Gagliardini, P., Ossola, E., \& Scaillet, O. (2016). Time-varying risk premium in large cross-sectional equity data sets. Econometrica, 84(3), 985-1046.

Granger, C. W. J. (1975). A survey of empirical studies on capital markets. International Capital Markets, 3-36.

Guidi, F., \& Gupta, R. (2012). Forecasting volatility of the ASEAN-5 stock markets: a nonlinear approach with non-normal errors. Discussion Papers Finance (14).

Hawawini, G. (1984). European equity markets: Price behavior and efficiency, monograph series in Finance and Economics.

Ito, M., \& Sugiyama, S. (2009). Measuring the degree of time varying market inefficiency. Economics Letters, 103(1), 62-64. https://doi.org/10.1016/j.econlet.2009.01.028

Jegadeesh, N., \& Titman, S. (1993). Returns to buying winners and selling losers: Implications for stock market efficiency. The Journal of Finance, 48(1), 65-91.

Jensen, M. C. (1968). The performance of mutual funds in the period 1945-1964. The Journal of Finance, 23(2), 389-416.

Kahneman, D., \& Tversky, A. (1979). Prospect Theory: An Analysis of Decision Under Risk, Econometrica, vol. 47, pp 263-291.

Kim, J. H., Shamsuddin, A., \& Lim, K. P. (2011). Stock return predictability and the adaptive markets hypothesis: Evidence from century-long U.S. data. Journal of Empirical Finance, 18(5), 868-879. https://doi.org/10.1016/j.jempfin.2011.08.002

Kiwiriyakun, M. (2013). The Risk-Return Relationship in Asean-5 Stock Markets: An Empirical Study Using Capital Asset Pricing Model. Faculty of Economics, Thammasat University.

Lim, K.-P. (2007). Ranking market efficiency for stock markets: A nonlinear perspective. Physica A: Statistical Mechanics and Its Applications, 376, 445-454.

Lim, K.-P., \& Brooks, R. D. (2006). The evolving and relative efficiencies of stock markets: Empirical evidence from rolling bicorrelation test statistics. Available at SSRN 931071.

Ljung, G. M., \& Box, G. E. P. (1978). On a measure of lack of fit in time series models. Biometrika, 65(2), 297-303.

Lo, A. (2004). The adaptive market hypothesis: market efficiency from an evolutionary perspective. The Journal of Portfolio Management, 30(5), 15-29.

Lo, A. W. (1997). Market Efficiency. Edward Elgar Publishing.

Lo, A. W. (2004). The adaptive markets hypothesis. The Journal of Portfolio Management, $30(5), 15-29$.

Lo, A. W. (2005). Reconciling Efficient Market with Behavioral Finance: The ADAPTIVE MARKETS HYPOTHESIS. The Journal of Investment Consulting, 7(2), 1-25. https://doi.org/10.2139/ssrn.728864

Lo, A. W., \& MacKinlay, A. C. (1988). Stock market prices do not follow random walks: Evidence from a simple specification test. The Review of Financial Studies, 1(1), 4166.

Malkiel, B. G. (2007). A Random Walk Down Wall Street:: the Time-tested Strategy for Successful Investing. 2003. WW Norton \& Company.

Malkiel, B. G., \& Fama, E. F. (1970). Efficient capital markets: A review of theory and empirical work. The Journal of Finance, 25(2), 383-417. 
Reilly, F. K., \& Brown, K. C. (2011). Investment analysis and portfolio management. Cengage Learning.

Roll, R. (1977). A critique of the asset pricing theory's tests Part I: On past and potential testability of the theory. Journal of Financial Economics, 4(2), 129-176.

Ross, S. A. (1976). The arbitrage theory of capital asset pricing, 'Journal of Economic Theory'. Elsevier, Amsterdam.

Sharpe, W. F. (1966). Mutual fund performance. The Journal of Business, 39(1), 119-138.

Shefrin, H., \& Statman, M. (2000). Behavioral Portfolio Theory. The Journal of Financial and Quantitative Analysis, 35(2), 127. https://doi.org/10.2307/2676187

Solnik, B. H. (1973). Note on the validity of the random walk for European stock prices. The Journal of Finance, 28(5), 1151-1159.

Wang, Y., \& Liu, L. (2016). Spillover effect in Asian financial markets: A VAR-structural GARCH analysis. China Finance Review International. 